\title{
Mujeres en transición Izquierda revolucionaria, igualdad de género y democratización. Una comparación entre El Salvador y Nicaragua ${ }^{1}$
}

\author{
Ilja A. Luciak ${ }^{2}$
}

Cuando una mujer llega a la política, cambia la mujer. Cuando las mujeres llegan a la política, cambia la política. Poder Femenino. Panfleto electoral del FMLN

\section{Resumen}

En este artículo, el autor examina el problema de género tal como éste es enfrentado por el FSLN, en Nicaragua, y el FMLN en El Salvador. El trabajo se apoya en dos conceptos claves: el de género -entendido como la forma en que el sexo y la sexualidad se convierten en relaciones de poder en la sociedad-, y el de igualdad — que tiene tanto una dimensión formal como sustancial. Una de sus conclusiones más relevantes es que en el examen de las experiencias políticas de la izquierda salvadoreña y nicaragüense, es preciso discernir entre los avances positivos en términos de igualdad formal, y una reformulación fundamental de las relaciones tradicionales de género, condición previa para la realización de una igualdad sustantiva.

1. Este artículo se ha publicado en el Journal of Inter-American Studies and World Affairs, 40, No. 1, 1998; y en Pensamiento Propio, enero-abril, 1998.

2. Ilja A. Luciak es profesor adjunto de Ciencias Políticas en el Instituto Politécnico de Virginia y en la Universidad Estatal de Virginia. Ha sido profesor invitado en la Universidad Centroamericana (UCA) en Managua, y es el autor de The Sandinista Legacy: Lessons from a political economy in transition. University Press of Florida, 


\section{Introducción}

En la era de la posguerra fría, la izquierda revolucionaria en América Central y el Caribe enfrenta nuevos retos. Los años setenta y ochenta se caracterizaron por la lucha contra la continuación y reimposición de la hegemonía estadounidense y el enfrentamiento con las élites domésticas que representaban los intereses del coloso del norte. Era un tiempo de debate en torno a la estrategia militar y la organización política adecuadas para alcanzar el poder a través de la lucha armada. La izquierda revolucionaria demostró ser un oponente formidable que adaptó con éxito sus tácticas para enfrentar nuevos retos.

La tarea principal en esta coyuntura histórica es de otra naturaleza. En América Central, en particular, la izquierda revolucionaria tiene que pasar de las organizaciones militares jerárquicas para convertirse en partidos políticos democráticos. EI cnfoque ha cambiado de la guerra a la consolidación de estructuras democráticas emergentes, y la izquierda revolucionaria debe demostrar a sus simpatizantes y al público en general que realmente representa una alternativa política viable.

Para lograr ese objetivo, la izquierda está obligada a reinventarse ideológicamente. Tras el colapso del 'socialismo real' en la Unión Soviética y Europa del Este, es mucho lo que se ha dicho en contra del paradigma socialista. La doctrina socialista tradicional debe replantearse para fortalecer su atractivo a los ojos del electorado, y la lucha por la justicia social y económica debe continuar sobre la base de nuevas premisas. Al respecto, la plena integración de las mujeres en las estructuras políticas emergentes y la inclusión de sus derechos en los programas de los partidos es de vital importancia. La lucha por la emancipación de las mujeres podría servir para revitalizar a la izquierda. Existe una creciente evidencia de que la izquierda revolucionaria —que en el pasado descuidó la lucha por los derechos de las mujeres- está empezando a revisar su manera de pensar. El surgimiento en los años noventa de un vital movimiento de mujeres ha sido, ciertamente, un factor clave en este proceso. El autor analiza aquí esta nueva realidad dentro del contexto centroamericano.
Al culminar en acuerdos de paz los conflictos militares en Nicaragua, El Salvador y Guatemala, la América Central en los noventa presenta una nueva realidad. Los movimientos guerrilleros de los tres países llevaron adelante su lucha bajo la bandera de la justicia social y económica para los pueblos. A dicha lucha se vincularon muchas mujeres con el ánimo de participar en la construcción de una nueva sociedad. Es importante dilucidar si la fuerte participación de las mujeres durante la guerra se está traduciendo en una representación efectiva en las estructuras políticas que han surgido o están en proceso de creación. La igualdad de género es un indicador central para evaluar si la izquierda revolucionaria está cumpliendo sus promesas hacia sus constituyentes femeninas. Entiendo el término género como una categoría producida a nivel social, definida en las palabras de Carver (1996, p. 120) como "la forma en que el sexo y la sexualidad se convierten en relaciones de poder en la sociedad". La igualdad se utiliza como un concepto doble que incluye "la igualdad formal, que se puede lograr por medio de la legislación" y la "igualdad substancial, que aspira a poder lidiar con las relaciones entre individuos en diferentes posiciones originales" (Parvikko, 1991, p. 48).

El enfoque está dirigido a establecer hasta qué punto las mujeres en Nicaragua y El Salvador han tenido éxito en cambiar las relaciones de género dentro de la izquierda revolucionaria y avanzar hacia una igualdad sustancial. Como evidencia de que las relaciones de género están cambiando, se analiza la representación de las mujeres dentro de las estructuras partidarias y las listas de candidatos para cargos públicos y asambleas legislativas. Aunque este enfoque enfatiza indicadores cuantitativos, el estudio de las estrategias utilizadas para lograr una mayor representación femenina proporciona el contexto para examinar la lucha por alcanzar igualdad sustantiva.

Con todo ello-se trata de dar un aporte a la literatura sobre género y democratización. Una considerable cantidad de trabajos analizan "la tercera ola de la democratización" (Huntington, 1991) que inició en los años setenta. Aunque el enfoque inicial de esa literatura estaba relacionado con el colapso de los regímenes autoritarios, el én-

1995. Ha escrito artículos sobre revolución, democratización, movimientos de base y políticas de género. Actualmente dirige las investigaciones para un libro sobre equidad de género y democratización en América Central.

Este trabajo ha sido posible gracias al apoyo de DIAKONIA-Suecia y de Church of Sweden AID. 
lasis actual está en la consolidación democrática. La principal limitación de esos escritos es el equiparamiento de la democracia con el constitucionalismo liberal. Ese enfoque normativo lleva a los analistas a subrayar la ausencia/existencia de la política partidaria competitiva, como el indicador central para la consolidación democrática en lugar de "la distribución más amplia del poder en la sociedad, lo que les permite ignorar las desigualdades de género" (Waylen, 1996, p. 118). Un creciente número de estudiosos de las transiciones democrálicas sostienen que sólo un análisis con enfoque de género sobre la democratización proporciona una visión válida de la realidad social y política de una sociedad en transición. El autor concuerda con csa premisa y busca contribuir a la discusión proporcionando datos desde el contexto centroamericano. Un estudio reciente realizado por el Banco Interamericano de Desarrollo (BID) afirma que "la democratización da a las mujeres y a otros grupos antes excluidos del proceso político, una mayor oportunidad de participar. Abre espacio para las mujeres en el ejercicio del poder dentro de ins(ituciones estatales y civiles" (BID, 1995, p. 87). Es hora de establecer si esas oportunidades verdaderamente existen y si se están haciendo realidad.

Los partidos políticos son actores claves en el proceso de la consolidación democrática. Aunque muchos dicen que comparten un compromiso hacia la igualdad, Alvarez (1990) demostró, en el caso brasileño, que a las mujeres se les continúa excluyendo de las decisiones importantes y que están sobrepresentadas en las estructuras partidarias. En lo que respecta a los cargos públicos, Waylen ha argumentado que a pocas mujeres se "les estaba nominando como candidatas de los partidos políticos en las primeras elecciones competitivas" después de la transición de un gobierno autoritario (Waylen, 1996, pp. 124-126).
Para comprender el historial de la izqulerda revolucionaria nicaragüense y salvadoreña con respecto a sus constituyentes femeninas, se comenzará con un breve antecedente histórico. Los dos partidos en los que se enfoca la discusión son el Frente Farabundo Martí para la Liberación Nacional de El Salvador (FMLN) y el Frente Sandinista de Liberación Nacional de Nicaragua (FSLN). El FMLN se convirtió en un partido político legal en 1992, tras firmarse los acuerdos de paz de Chapultepec entre representantes de la guerrilla y del gobierno salvadoreño. El FMLN tuvo su primera prueba electoral en 1994, cuando participó en las primeras elecciones democráticas en la historia de El Salvador. El antiguo movimiento guerrillero obtuvo un respetable 21 por ciento del voto popular, convirtiéndose en el segundo partido más grande después del partido en el gobierno, la Alianza Republicana Nacionalista (ARENA). EI FMLN y ARENA fueron los principales protagonistas de las elecciones de marzo de 1997 que se analizan más

adelante?

El movimiento sandinista en Nicaragua liene una experiencia mucho mayor como actor político, dado que alcanzó el poder el 19 de julio de 1979 tras derrocar al régimen somocista. El FSLN gobernó Nicaragua hasta las elecciones de 1990, cuando fue derrotado por una coalición multipartidista conocida como la Unión Nacional Opositora (UNO), encabezada por Violeta Barrios de Chamorro. En 1990, el FSLN obtuvo el 40 por ciento de los votos, y continuó siendo el partido político individual más fuerte. Tras la desintegración de la UNO, el principal rival del FSLN en las elecciones de octubre de 1996, que son las que se discuten en este documento, fue la Alianza Liberal (AL).

A partir de este hecho se analizan, desde una perspectiva de género, las elecciones nicaragüenses de 1996 y las parlamentarias salvadoreñas de

3. Los otros partidos que participaron en las elecciones fueron el Demócrata Cristiano (PDC), el de Conciliación Nacional (PCN), la Convergencia Democrática (CD), el Movimiento de Unidad (MU), el Movimiento de Solidaridad Nacional (MSN), el Partido Liberal Democrático (PLD), el Partido Renovación Social Cristiano (PRSC), el Partido Demócrata (PD), el Partido Movimiento Auténtico Social (MAS), el Pueblo Libre (PL), el Partido Pueblo Unido Nucvo Trato (PUNTO). 


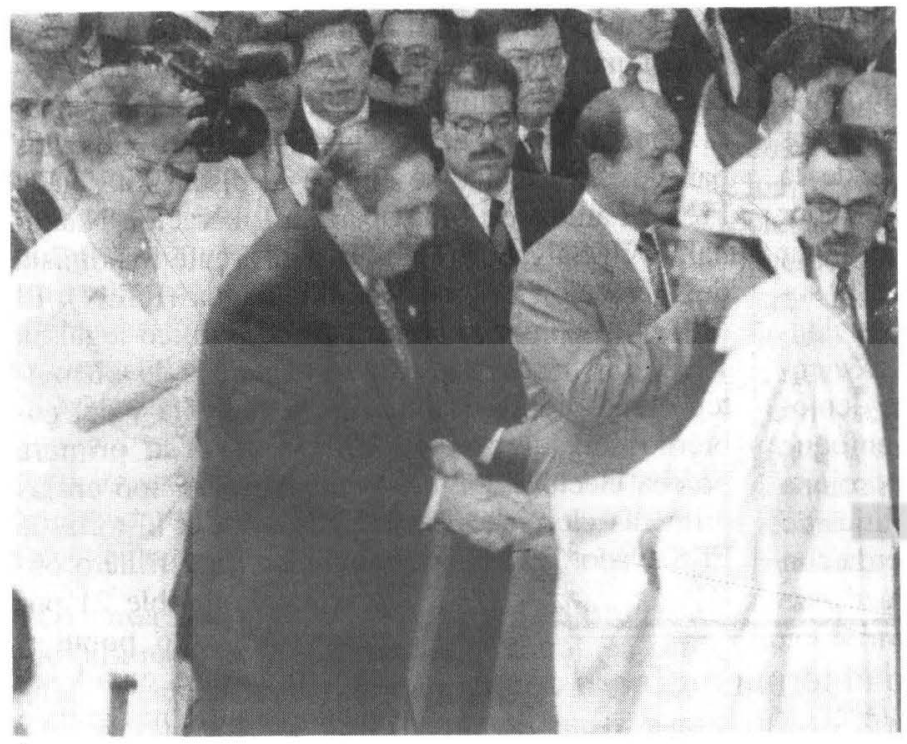

mentar la representación de las mujeres. Luego se examinan los resultados de las elecciones en El Salvador y Nicaragua a fin de establecer si las mujeres han fortalecido su representación formal, y se concluye con una discusión sobre las lecciones que se pueden aprender de un análisis comparativo de los dos casos.

\section{La agenda estratégica de la igual-} dad de género ${ }^{4}$

En el caso de El Salvador, el programa del partido FMLN hacía referencia específica a las mujeres:

"La construcción de una verdadera democracia conlleva la plena realización de los derechos de las mujeres y su participación creativa en todas las esferas de la vida nacional. Esto es un principio

1997. Un excelente estudio sobre las elecciones anteriores en los dos países encontró diferencias significativas en el contenido de género de esas experiencias electorales. En lo que respecta a las elecciones nicaragüenses de 1990, Kampwirth (1995, pp. 1-2) argumenta que "desde una perspectiva feminista, las primeras elecciones en Nicaragua después de la guerra civil fueron casi un desastre", mientras que, por otro lado, reconoce el importante papel que desempeñaron las feministas organizadas en el caso de El Salvador.

Esta investigación inicia con una discusión sobre los esfuerzos realizados por los movimientos de mujeres en El Salvador y Nicaragua por colocar la igualdad de género en la agenda política. Seguidamente, se analiza hasta qué punto esos esfuerzos se tradujeron en una importante representación de las mujeres en las listas de candidatos de sus respectivos partidos. Se pone especial énfasis en las estrategias innovadoras utilizadas por militantes femeninas para au- fundamental en el proyecto de sociedad por el cual lucha el FMLN. Tenemos el compromiso de alcanzar la igualdad de derechos para las mujeres y de superar su marginación y opresión en la sociedad salvadoreña" (FMLN, 1993, p. 19).

La Secretaría de la Mujer del FMLN fue una protagonista clave en la lucha por asegurar que estas palabras se convirtieran en realidad.
Es importante dilucidar si la fuerte participación de las mujeres durante la guerra se está traduciendo en una representación efectiva en las estructuras políticas que han surgido o están en proceso de creación.
En un principio, la secretaría luchó por la introducción de medidas de discriminación positiva como cuotas, con el argumento de que debido a su importante participación en la guerra, las mujeres se habían ganado el derecho a participar en las estructuras partidarias. Las militantes ciertamente tenían un fuerte argumento. De los 15,009 miembros del FMLN que fueron oficialmente desmovilizados, 4,492 ó el 29.9 por ciento eran mujeres (Luciak, 1998). Las mujeres podían señalar la experiencia de otros partidos progresistas, particularmente en Chile, donde en el

4. Este relato se basa en entrevistas con "Nidia Díaz" (María Marta Valladares), Deysi Cheyne, Violeta Menjívar, Lorena Peña, Irma Amaya y Sonia Cansino en El Salvador. En Nicaragua se entrevistó a Daisy Zamora, Alba Palacios, Esmeralda Dávila, Azucena Ferrey, María Teresa Blandón, Marta Valle, Venigna Mendiola, Mónica Zalaquett, Dorotea Wilson y Mónica Baltodano. 
caso del Partido Humanista y otros partidos de la izquierda, este tipo de medidas favoreció un gran influjo de mujeres al partido y la selección de un importante número de candidatas para cargos públicos (Molina, 1989; Hecht Oppenheim, 1995, p. 5).

Inicialmente, los esfuerzos de la secretaría no tuvieron mucho éxito. Por ejemplo, sus miembros no lograron convencer a los líderes del partido para que aceptaran una cuota del 30 por ciento para las mujeres en la selección de los candidatos para las elecciones parlamentarias de 1994. Las militantes del FMLN, sin embargo, siguieron insistiendo y argumentaron a favor de cambios dentro de las propias estructuras partidarias. El liderazgo del partido acordó establecer un compromiso político y garantizar que las mujeres estarían representadas en las estructuras partidarias, sobre la base del número de mujeres miembros del partido. Este compromiso se implementó por primera vez en la convención nacional del partido -que se celebró en diciembre de 1995- y resultó en la elección de mujeres a un tercio de las posiciones en las instancias de toma de decisiones a nivel nacional. Cuando se realizó la convención, el FMLN tenía registrados 28,000 miembros, una tercera parte de los cuales eran mujeres. En ese entonces, las cifras de la membresía del FMLN estaban cambiando de manera constante debido a una campaña continua para volver a afiliar a la membresía. El proceso de reafiliación de los simpatizantes del partido había iniciado unos meses atrás, cuando los líderes del FMLN decidieron adoptar esa medida para hacer pública su decisión de disolver los cinco grupos que originalmente conformaron el FMLN y encaminarse hacia una estructura de partido único. Hasta 1995, cinco grupos distintos constituían el FMLN, las Fuerzas Populares de Liberación (FPL), el Ejército Revolucionario del Pueblo (ERP), las Fuerzas Armadas de Liberación (FAL, del Partido Comunista), la Resistencia Nacional (RN) y el Partido Revolucionario de los Trabajadores Centroamericanos (PRTC).

La relativa influencia de las mujeres en el partido se mantuvo bastante estable a medida que el partido continuaba reafiliando a sus miembros. $\mathrm{Pa}$ ra marzo de 1996, el FMLN registraba un total de 33,000 miembros, de los cuales 10,890 -el 33 por ciento- eran mujeres. A medida que empezó a calentarse la campaña electoral, se dio menos atención al esfuerzo por recuperar la membresfa, y éste procedió a un paso más lento. En marzo de 1997, las fuentes del FMLN sostenían que contaban con una membresía de 40,000 a 80,000 (Spence, et al., 1997, p. 25). Los cálculos más altos parecen basarse en cifras mayores $y$, según uno de los tres coordinadores del partido, los números estaban por debajo de los 50,000 y un tercio eran mujeres. Sobre la base de esos cálculos, las mujeres del FMLN lucharon por una cuota del 35 por ciento, la que fue aprobada por el liderazgo del partido y se convirtió en parte de las reglas internas que gobernaban el proceso de selección de los candidatos.

La Secretaría de la Mujer había tratado de aumentar de manera significativa el número de mujeres afiliadas al partido pero, como lo reconocen sus líderes, no habían logrado alcanzar ese objetivo (Menjívar, entrevista del 6 de febrero de 1997). Además, debido a la falta de recursos financieros, la secretaría no pudo implementar una serie de talleres y seminarios diseñados para fortalecer la sensibilidad de género dentro del partido. A pesar de esas dificultades, logró hacer que el liderazgo del partido incorporara la agenda de los derechos de las mujeres en la propuesta socioeconómica del FMLN, un documento que planteaba las políticas del partido para el futuro de El Salvador. Aún más significativo fue el acuerdo que obtuvieron de los líderes del partido, que daba a las mujeres candidatas total autonomía para conducir su campaña. Esto se hizo en un esfuerzo por asegurar que la precaria situación financiera del partido no afectara de manera negativa a las candidatas, quienes esperaban que se les asignaran menos recursos que a sus contrapartes masculinos. Para dar una idea de los limitados recursos con que contaban para la campaña, basta señalar que a "Nidia Díaz"s (María Marta Valladares), la vicecoordinadora del FMLN, le dieron menos de 900 dólares para la campaña electoral del partido en el departamento de San Vicente.

Las mujeres del FMLN establecieron el Comando Electoral de Mujeres para coordinar sus esfuerzos. El Comando estaba encabezado por cuatro mujeres que representaban a las candidatas y a la Secretaría de la Mujer. Su estrategia consistía

5. Varios ex guerrilleros continúan utilizando sus seudónimos de guerra en lugar de sus nombres legales. 
en lograr tres objetivos: (1) diseñar una plataforma para las mujeres con el fin de que el electorado supiera con claridad cuáles eran las posiciones de las candidatas; (2) enfatizar la importancia de dar visibilidad a las candidatas en la campaña electoral; (3) cabildear dentro del FMLN para asegurar que en la campaña electoral en su conjunto se promovieran los temas de las mujeres. El Comando compuso una canción para la campaña electoral, diseñó propaganda y afiches, y organizó anuncios en la radio y la televisión. También estableció brigadas de tres a cinco mujeres, quienes hicieron campaña casa por casa cabildeando para candidatas a alcalde. Además, las mujeres tuvieron tanto éxito al obtener precios favorables por parte de mujeres jefas de empresas de publicidad, que sus colegas masculinos les rogaron que también negociaran a nombre de ellos (Peña, entrevista del 7 de febrero de 1997). Los hombres se mostraban igual de entusiasmados por utilizar la propaganda diseñada por el Comando para sus propias campañas electorales, hasta tal punto, que el Comando tuvo que impedirlo para asegurar que hubiera disponibilidad de recursos para las candidatas. El éxito del Comando fue evidente en las calles de la capital, donde los rostros de las candidatas del FMLN estaban omnipresentes, mientras que los candidatos luvieron poca presencia.

Las mujeres miembros del Comando también participaron en un esfuerzo mayor -iniciado por representantes del movimiento de mujeres salvadoreñas - para colocar los temas de las mujeres en la agenda electoral. Con esta iniciativa se tenía la intención de partir de la experiencia de Mujeres '94, una coalición multipartidaria de mujeres que trabajaron para aumentar el volo femenino, persuadir a los partidos para que incluyeran las demandas de las mujeres en sus plataformas y elegir candidatas (Saint-Germain, sin fecha, p. 19; Kampwirth, 1995). A inicios de enero de 1993, representantes de un número de organizaciones de mujeres habían empezado a trabajar para "una coalición amplia para presionar por las demandas de las mujeres" (Saint-Germain, 1995, p. 18). Después de concluir que a las mujeres se les había marginado en los acuerdos de paz, trataron de presionar a los partidos políticos, que estaban compitiendo en las elecciones de 1994, para que apoyaran una plataforma que propugnaba los derechos de la mujer.

En febrero de 1996, representantes del movimiento de mujeres se reunieron para evaluar la experiencia de Mujeres '94. La primera tarea de esa asamblea de mujeres fue revisar y actualizar la plataforma de $1994^{6}$. El grupo de mujeres que trabajaban de manera constante en esa tarea era bastante reducido ${ }^{7}$. Durante 1996 se puso de manifiesto que varios temas claves dividían a las mujeres que formaban parte de la Iniciativa de Mujeres por la Igualdad en la Participación Política, como oficialmente se llamaba el grupo. En 1994, la principal discrepancia había sido la doble militancia (la participación activa en dos movimientos o par(idos). El asunto era si las mujeres que participaban en Mujeres ' 94 como representantes del movimiento de mujeres podían también ser militantes activas de un partido. Las principales contendientes en esa dispula eran el Movimiento de Mujeres "Mélida Anaya Montes" (o MAM) y las Mujeres por la Dignidad y la Vida (o Las Dignas). Las Dignas consideraban que la militancia partidaria era incompatible con la autonomía propia como activista del movimiento de mujeres. Las Mélidas no compartían esa posición, argumentando a favor de la posibilidad de combinar ambas funciones. Esta controversia tenía sus orígenes en la lucha por la autonomía, un tema sobresaliente para varios grupos de mujeres que surgieron en los noventa y que tenían vínculos cercanos con el FMLN. El dilema entre la autonomía y la integración que enfrentaban las militantes del FMLN era un tema que confrontaba a las mujeres en muchas sociedades latinoamericanas en transición de un gobierno autoritario a políticas más democráticas. En toda la región, las activistas argumentaban que los partidos políticos las estaban utilizando, y mu-

6. Ver Saint-Germain (sin fecha) para una discusión de la plataforma de 1994 y el esluerzo organizativo del movimiento de mujeres.

7. Las principales organizaciones que participaron en el esfuerzo de 1996-1997 fueron el Movimiento de Mujeres "Mélida Anaya Montes" (MAM), las Mujeres por la Dignidad y la Vida (Las Dignas), el Instiluto de Investigación, Capacitación y Desarrollo de la Mujer (IMU), el Movimiento Salvadoreño de la Mujer (MSM) y la Asociación de Madres Demandantes. Además, un número de mujeres independientes se unieron al grupo para sus reuniones regulares de desayuno los días miércoles. Por ejemplo, en un taller organizado en febrero de 1997. para linalizar la plataforma electoral, estuvieron representadas 27 organizaciones. 
chas cortaron todo contacto. Para mediados de 1990, sin embargo, muchas mujeres veían el tema "no como una opción entre autonomía o integración, sino como una necesidad de ambas" (Waylen, 1996, pp. 133-134).

Tanto Las Dignas como Las Mélidas fueron originalmente fundadas por militantes del FMLN. Las Dignas fueron establecidas por miembros de la Resistencia Nacional, mientras que el grupo de Las Mélidas se creó del esfuerzo de mujeres leales a las Fuerzas Populares de Liberación. Según entrevistas con varias militantes de alto rango, los grupos de mujeres creados por el FMLN se utilizaban a menudo para asegurar fondos por parte de agencias de desarrollo interesadas en apoyar la organización de las mujeres. Esos fondos, sin embargo, los controlaba la dirección del partido, y eran ellos mismos quienes decidían sobre su uso. No es de extrañarse que las militantes se resintieran a que se las tratara como fichas para recaudar fondos para las arcas del partido. Las Dignas fueron las primeras en separarse con su grupo y se han vuelto fervientes defensoras de su autonomía. Las Mélidas declararon su independencia de las FPL un par de años más tarde. A diferencia de Las Dignas, sin embargo, las Mélidas siguen activas dentro del FMLN.

Tres años más tarde, el tema de la imparcialidad había reemplazado el problema de la doble militancia. Las mujeres afiliadas a Las Dignas argumentaban que la coalición de mujeres debía trabajar de manera imparcial y promover candidatas sin importar su ideología, mientras que la mayoría cra de la opinión que todas eran mujeres que apoyaban partidos de la izquierda del espectro ideológico y que, por lo tanto, no podían trabajar en nombre de sus rivales políticas. Una mujer lo resumió diciendo: "Somos mujeres de la izquierda y no podemos invitar al pueblo a que vote por las mujeres de ARENA". Esta posición tenía mucho sentido desde el punto de vista de Las Mćlidas. No sólo era Irma Amaya la coordinadora del movimiento y candidata a la Asamblea Nacional, sino que otras cuatro candidatas del FMLN eran miembros del MAM (todas resultaron electas, incluyendo a Amaya).

Al final, el grupo adoptó un enfoque no partidario que se reflejaba en el lema "Mujer, vota por tí misma" y con mu- chas participantes preguntándose sobre la efectivl. dad de dicho enfoque. Debido a estas disputas internas, la tarea vital de llegar a un acuerdo sobre una agenda común no se logró sino hasta febrero de 1997, un año después de que iniciara todo el esfuerzo organizativo. En las palabras de Deysi Cheyne (entrevista del 19 de marzo de 1997), una protagonista clave, "ésta fue una barrera que nunca logramos superar. Nunca pudimos llegar a un acuerdo, y eso hizo que discutiéramos por semanas enteras". Esta demora truncó el principal objetivo del esfuerzo organizativo, como era lograr que los partidos firmaran la plataforma y se comprometieran a implementar una agenda a favor de los derechos de las mujeres. De hecho, la versión final de la plataforma salió por primera vez el 10 de marzo (6 días antes de las elecciones), cuando se invitó a los representantes de todos los partidos para su presentación. Sólo tres partidos, ARENA, el FMLN y la Coalición (los tres partidos que apoyaban un candidato conjunto para el cargo de alcalde de San Salvador), se molestaron en asistir y, como era de esperarse, coincidieron en negarse a firmar el acta de compromiso. El argumento obvio fue que no podían comprometer sus partidos con un documento que nadie había visto antes de la reunión. Las desilusionadas mujeres no tenían a quien culpar, más que a ellas mismas.

A diferencia de la experiencia salvadoreña -donde hasta hace poco las declaraciones relacionadas con los derechos de la mujer estaban visiblemente ausentes de los documentos partidarios del FMLN-, el compromiso sandinista con la emancipación de las mujeres en Nicaragua ya se expresaba en el Programa Histórico del FSLN de 1969. Según ese documento, la revolución sandi- 
nista "abolirá la obvia discriminación a la que han sido sometidas las mujeres en relación con los hombres, y establecerá la igualdad económica, política y cultural entre mujeres y hombres" (FSLN, 1969, p. 32). Sin embargo, a pesar de la vigorosa parlicipación de las mujeres en la revolución, donde representaron un 30 por ciento de los combatientes, además de varios líderes, las mujeres estuvieron sobrepresentadas en las instancias de toma de decisiones del gobierno revolucionario (Chuchryk, 1991, p. 143; Ramírez-Horton, 1982, p. 152; Randall, 1981, p. IV; Reif, 1986, p. 158). En la opinión de Paola Pérez (1990, pp. 194-195), el historial sandinista durante los años ochenta con respecto a sus constituyentes femeninas fue mixto. Mejoras en el área de los intereses prácticos de género - como el acceso a la salud y la educación- coexistieron con la continuación de "relaciones de género opresivas" en el ámbito privado". Dentro del propio partido sandinista se excluyó a las mujeres de la dirección nacional hasta 1994.

Dorotea Wilson, una de las cinco mujeres electas en 1994 a la dirección nacional (compuesta por 13 miembros) y una de las principales defensoras de la igualdad de género dentro del partido, señaló que el esfuerzo concertado por aumentar la representación de las mujeres dentro del FSLN inició en 1991. En ese entonces, Dora María Téllez, quien estaba propuesta para un escaño en la dirección nacional, no logró resultar elecla. Tras su derrota, las militantes redoblaron sus esfuerzos. En 1994, en ocasión de la siguiente convención nacional, las mujeres miembros del partido exigieron que el 50 por cicnto de todas las posiciones en las estructuras partidarias se asignaran a mujeres. Esta demanda poco realista formaba parte de una estrategia consciente de hacer una contrapropuesta a la oferta del liderazgo de un 25 por ciento (Wilson, entrevista del 5 de febrero de 1997). La estrategia de las mujeres demostró ser exitosa al revisarse los estatutos del partido para asignar a las mujeres un mínimo del 30 por ciento de todos los cargos. Esta cuota era la que se aplicaría en la selección de los candidatos para las elecciones de 1996.

En su lucha por la igualdad de género, las militantes tuvieron el apoyo de la Asociación de Mujeres Nicaragüenses Luisa Amanda Espinoza, o
AMNLAE, la organización de mujeres sandinistas. Este movimiento desempeñó una función clave en la lucha por aumentar la participación de las mujeres dentro del partido. AMNLAE, a la que le había faltado autonomía bajo el gobierno sandinista, se estaba esforzando por evolucionar hacia un movimiento no partidista de base amplia. Como parte de esa estrategia buscó a otros sectores del movimiento de mujeres y participó en la Coalición Nacional de Mujeres.

La Coalición surgió por iniciativa de un grupo de mujeres que desempeñaban diferentes funciones en el gobierno de Violeta Chamorro. Ellas consideraban importante que las mujeres afiliadas a la derecha política reconsideraran sus puntos de vista sobre el movimiento de mujeres, al que habían descartado como controlado por el partido sandinista. Se organizaron varios seminarios para familiarizar a los diferentes sectores entre sí. La idea era que todas las participantes unieran fuerzas para combatir la discriminación en contra de las mujeres. Según María Teresa Blandón, quien ayudó a organizar estos primeros encuentros, en un inicio era un reto incluso llegar a un consenso sobre si verdaderamente se discriminaba a las mujeres en la sociedad nicaragüense. Por ejemplo, Azucena Ferrey, antigua líder de la Resistencia Nicaragüense y miembro de la Asamblea, adoptó la posición de que ella no estaba subordinada, que tenía poder y que siempre había podido lograr lo que quería (Blandón, entrevista del 4 de febrero de 1997). La posición de Ferrey reflejaba su desconfianza hacia las opiniones de las "feministas sandinistas", más que una falta de reconocimiento sobre la discriminación a la que estaban sometidas las mujeres en la sociedad nicaragüense. El 8 de marzo de 1987, Ferrey convocó a una concentración en honor al Día Internacional de la Mujer y para exponer la situación de las mujeres que no estaban a favor de la revolución sandinista. Esa manifestación fue brutalmente reprimida por la Policía Sandinista (encabezada por Doris Tijerino, una de las comandantes históricas del FSLN). No fue sino hasta principios de 1990, cuando Ferrey y Tijerino ocuparon cargos en la Asamblea Nacional, que las dos mujeres pudieron iniciar un diálogo que les permitió superar los límites ideológicos y unirse en la lucha por la emancipación de las mu-

8. Ver también Luciak (1995, pp. 161-181) para un análisis sobre las políticas sandinistas hacia las mujeres rurales. 
jeres (Ferrey, entrevista del 12 de noviembre de 1997). Hubo, entonces, un lento proceso hasta que estas mujeres de diferentes orígenes pudieron acordar una estrategia para "luchar por los derechos de las mujeres y la transformación de las maneras tradicionales de hacer política" (Coalición, 1996, p. 3).

Las mujeres elaboraron una agenda mínima que incluía un llamado a favor de sus derechos en el ámbito político y socioeconómico (Chávez Metoyer, 1997, p. 14). Todas las demandas que se incluían en la agenda eran producto de un consenso. A pesar de ese proceso tan complicado, las participantes lograron incluir temas controversiales, como la oferta de servicios de salud reproductiva (Coalición, 1996, p. 10). Para poder defender de manera eficaz la agenda mínima en la arena política, las mujeres decidieron organizarse en la Coalición Nacional de Mujeres. La primera tarea oficial de la Coalición fue organizar eventos para el 8 de marzo de 1996, en celebración del día internacional de la mujer. Por primera vez, mujeres de todo el espectro político unieron fuerzas con feministas, lesbianas y grupos autónomos de mujeres para celebrar este evento. Posteriormente, la Coalición se reunió con representantes de los partidos políticos a fin de obtener su compromiso de implementar la agenda en caso de salir electos. Varios partidos, incluyendo al FSLN, el Partido de la Resistencia Nicaragüense y la Coalición UNO '96, firmaron un acta de compromiso. Lo más notorio fue que la Alianza Liberal se negó a firmar.

Al igual que en el caso de El Salvador, uno de los principales debates dentro de la Coalición era si apoyar a candidalas individuales o promover la participación de la mujer en las elecciones como tal. Las mujeres miembros de la Coalición que eran militantes del partido se negaron a apoyar a las candidatas nominadas por opositores ideológicos, mientras que a muchas feministas no les interesaba apoyar a candidatas, pues en su opinión "ni una sola era feminista" (Blandón, entrevista del 4 de febrero de 1997). Este conflicto nunca fue re- suelto y limitó la efectividad del trabajo de la Conlición. Irónicamente, al estar inmersas en sus propias campañas, las candidatas tenían poco tiempo disponible para promover el trabajo de la Coallción. Fue así como el trabajo de la Coalición lo realizaron fundamentalmente feministas, pero cuando se trataba de eventos públicos que las feministas habían organizado y para los cuales habían escrito discursos, las candidatas les pedían que permanecieran invisibles por miedo a "quemarse" al ser asociadas con grupos "radicales" (Blandón, entrevista del 4 de febrero de 1997).

La experiencia nicaragüense no estuvo exenta de conflictos. A diferencia de sus contrapartes salvadoreñas, sin embargo, las mujeres organizadas en la Coalición se mostraron eficaces para forjar una alianza pluralista que presentaba un frente unido con respecto a los partidos políticos. Más importante aún fue que finalizaron su agenda más de seis meses antes de las elecciones, dando al movimiento suficiente tiempo para cabildear con las instituciones políticas. Los esfuerzos de la Coalición no hubieran sido posibles sin el vital apoyo financiero proporcionado fundamentalmente por organizaciones gubernamentales y no gubernamentales de los países escandinavos ${ }^{9}$. Eivur Halkjaer, Embajadora de Suecia, considerada por la Coalición como "nuestra madrina", fue una figura clave en ese esfuerzo (Zalaquett, entrevista del 4 de febrero de 1997). El hecho de que la Coalición también recibiera fondos de la USAID evidencia que verdaderamente se consideraba un esfuerzo pluralista y multipartidario (Chávez Metoyer, 1997, p. 13).

\section{El proceso de selección del candidato: "La trenza" y otras estrategias innovadoras}

Las militantes del FMLN y del FSLN desarroIlaron estrategias innovadoras para aumentar su representación en las listas de candidatos ${ }^{10}$. Como ya se dijo, la primera línea de acción era lograr que los líderes del partido adoptaran una cuota, es

9. L.os gobiernos escandinavos estuvieron entre los primeros en incorporar la igualdad de género como un objetivo clave en sus programas de asistencia. En el caso de Suecia, la Autoridad Sueca para el Desarrollo Internacional (ASDI) seleccionó a Nicaragua como un país modelo para implementar un programa de ayuda en el que se enfatizaba la igualdad de género.

10. El relato sobre el proceso de selección de candidatas se basa en entrevistas con Nidia Díaz, Violeta Menjívar, Lorena Peña, Gerson Martínez, Irma Amaya y Sonia Cansino en El Salvador. En Nicaragua entrevisté a Daisy Zamora, Alba Palacios, Esmeralda Dávila, María Teresa Blandón, Marta Valle, Benigna Mendiola, Dorotea Wilson, Mónica Baltodano y Orlando Núñez. 
decir, un mínimo porcentaje de candidatas. La idea provino de la lucha por aumentar la participación de las mujeres dentro de las estructuras partidarias. $\mathrm{El}$ paso siguiente fue asegurar que la cuota se cumpliera en la selección de candidatos departamentales y municipales.

Además, las mujeres estaban bastante conscientes del requisito principal para ser un candidato exitoso bajo un sistema de representación proporcional, como es ocupar una buena posición en la lista de candidatos $^{\prime \prime}$. Sólo un candidato en esa posición estaba seguro de ser electo, suponiendo que el parlido obtendría el mismo número de votos que había alcanzado en la última contienda electoral ${ }^{12}$. Los militantes del partido podían conceder la cuota numérica y argumentar su adherencia a la igualdad formal, sin tener que incurrir en ningún costo real en términos de una mayor competencia por parte de las mujeres, así que el peso relativo de las mujeres no significaba mucho, sino que más bien tenían que luchar para que se les colocara en primer término en las listas departamentales y en posiciones muy altas en la lista nacional. En ambos países las mujeres se beneficiaron del hecho de que "los sistemas electorales con representación proporcional (RP) resultan en una mejor representación de las mujeres que en el caso de sistemas electorales mayoritarios" (Matland y Taylor, 1997, p. 186).
En junio de 1996, cuando unas 50 convenciones municipales (de 262) ya habían seleccionado sus candidatos en El Salvador, la Secretaría de la Mujer del FMLN realizó una encuesta y encontró que ni una sola mujer había sido propuesta como candidata para alcalde, y que pocas mujeres estaban propuestas para los consejos municipales. Al ver esta situación, varias líderes fueron a "asustar" a la comisión política del FMLN, y lograron que comunicara a todos los departamentos que debían observar la cuota a nivel municipal y departamental" (Peña, entrevista del 6 de febrero de 1997).

En las elecciones parlamentarias de 1994 en El Salvador, las militantes habían logrado colocar a 21 mujeres en las listas del partido, lo que representaba al 25 por ciento de los 84 candidatos. Fue a nivel nacional que las mujeres tuvieron mayor éxito. Allí representaban al 35 por ciento de los candidatos y al 40 por ciento de los suplentes. Ana Guadalupe Martínez y Lorena Peña, quienes ocupaban el segundo y el tercer puesto, respectivamente, resultaron electas en la lista nacional. Además, dos mujeres, Norma Guevara y Sonia Aguiñada, quienes ocupaban el cuarto y el quinto lugar en el departamento de San Salvador, también resultaron electas, al igual que "Nidia Díaz", la única mujer que encabezaba una lista departamental.

\section{Cuadro 1}

Composición de género de los candidatos del FMLN a la Asamblea Legislativa, 1994-1997

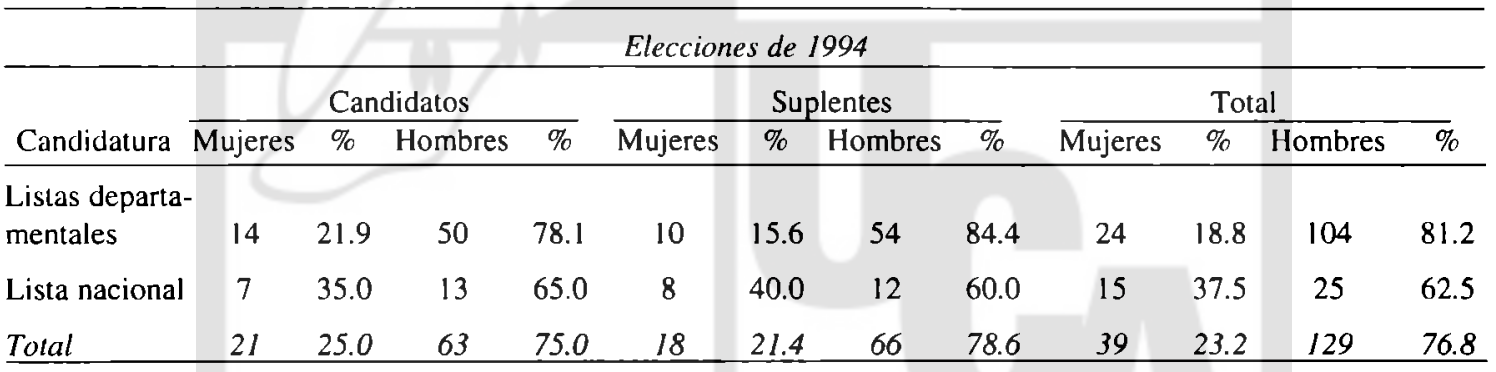

11. En el caso de gran parte de las listas departamentales, sólo los candidatos en los primeros puestos tenían buenas posibilidades de ser electos. Para la lista nacional, una posición "segura" significaba estar entre los primeros cinco candidatos.

12. En ambos países los candidatos se eligen de las listas departamentales elaboradas por los partidos, y donde el número de representantes de cada departamento está determinado por la cifra de su población. Además, hay una lista nacional que consiste en 20 escaños que son asignados sobre la base del número total de votos que obtenga un partido. 
Cuadro 1 (continuación)

Elecciones de 1997

\begin{tabular}{|c|c|c|c|c|c|c|c|c|c|c|c|c|}
\hline \multirow[b]{2}{*}{ Candidatura } & \multicolumn{4}{|c|}{ Candidatos } & \multicolumn{4}{|c|}{ Suplentes } & \multicolumn{4}{|c|}{ Total } \\
\hline & Mujeres & $\%$ & Hombres & $\%$ & Mujeres & $\%$ & Hombres & $\%$ & Mujeres & $\%$ & Hombres & $\%$ \\
\hline $\begin{array}{l}\text { Listas departa- } \\
\text { mentales }\end{array}$ & 15 & 23.4 & 49 & 76.7 & 16 & 25.0 & 48 & 75.0 & 31 & 24.2 & 97 & 75.8 \\
\hline Lista nacional & 9 & 45.0 & 11 & 55.0 & 10 & 50.0 & 10 & 50.0 & 19 & 47.5 & 21 & 52.5 \\
\hline Total & 24 & 28.6 & 60 & 71.4 & 26 & 31.0 & 58 & 69.0 & 50 & 29.8 & 118 & 70.2 \\
\hline
\end{tabular}

Fuente:Secretaría Electoral del FMLN, en Las Dignas, Las Mujeres, p. 28. El segundo cuadro se basa en datos proporcionados por el FMLN.

En las elecciones de 1997 , las mujeres lograron ocupar posiciones altas que se consideraban seguras. Había 24 candidatas ( 28.6 por ciento) y 26 suplentes ( 30.1 por ciento) para la Asamblea. De las cinco posiciones altas que se consideraban seguras en la lista nacional, las mujeres ocuparon dos lugares. En el departamento de San Salvador, las mujeres ocuparon las dos posiciones más altas, al igual que el quinto lugar (también considerado seguro). Las candidatas también encabezaban las listas departamentales en Santa Ana, Chalatenango y San Vicente. En general, en cuatro de los catorce departamentos las mujeres encabezaban las listas de candidatos. Con base en los resultados electorales de 1994, se consideraba que 7 mujeres ocupaban posiciones seguras. A la luz de las encuestas positivas, sin embargo, las mujeres líderes en el FMLN esperaban que un mínimo de 8 mujeres resultaran electas, y consideraban que hasta 10 representantes mujeres era un resultado realista. Según sus cálculos, habían asegurado que el 35 por ciento de las posiciones seguras estuviesen ocupadas por mujeres candidatas.

La mejoría en las posibilidades de que las candidatas mujeres resultaran electas no fue un accidente, sino evidencia de un arduo trabajo por parte de las militantes para convencer a sus contrapartes masculinos a aceptar la igualdad de género dentro del partido. Las cifras indican que sus esfuerzos fueron más exitosos a nivel nacional que departamental. Entrevistas con los líderes del partido y con candidatas respaldan la visión de que el tema de la igualdad de género tuvo apoyo a nivel nacional, al mismo tiempo que prevaleció una resistencia considerable a cualquier tipo de programas de "acción afirmativa" para las mujeres, tanto a nivel departamental como local. Sin embargo, no se puede generalizar esta situación, ya que hubo diferencias considerables entre todos los departamentos. En varios de ellos, especialmente en San Salvador, las mujeres forjaron alianzas eficaces con miembros masculinos del partido, y utilizaron una variedad de estrategias innovadoras para lograr que las candidatas fuesen incluidas en las listas.

El departamento de San Salvador tuvo un total de 16 candidatos y fue considerado un departamento difícil para que las mujeres resultaran electas, ya que tenían que competir con líderes masculinos de gran trayectoria. Al darse cuenta de que el FMLN no podía esperar ganar más de 8 escaños en este departamento, los líderes departamentales acordaron que debía haber al menos tres mujeres entre las primeras ocho posiciones. A fin de asegurar que todos los delegados votaran por al menos tres mujeres, los líderes departamentales acordaron que cualquier boleta que no incluyera los nombres de tres mujeres candidatas se declararía nula. El orden de los candidatos dependía del número total de votos recibidos. Según Violeta Menjívar (entrevista del 6 de febrero de 1997), quien encabezaba la lista de candidatos en el departamento, la reacción de muchos hombres fue vehemente, "esto es una violación de los derechos humanos; ésta es una imposición de las mujeres; ¿cuál es el significado de estas cuotas?; las mujeres no sirven para posiciones de liderazgo; cuando se les elige no cumplen...". Esta posición, sin embargo, estuvo más que compensada por aquellos hombres en el liderazgo departamental que no estaban interesados en las apariencias, pero que demostraron su apoyo por alcanzar igualdad substancial para las militantes. Fue así como la votación procedió según los planes. A las mujeres les fue mejor de lo que esperaban, con cuatro candidatas 
entre las primeras siete posiciones. Lo más sorprendente fue que las mujeres derrotaron a importantes líderes masculinos, como "Gerson Martínez" (Orlando Quinteros), el jefe de la bancada parlamentaria del FMLN, quien tenía una excelente reputación entre los simpatizantes del partido y quien llegó a ocupar la cuarta posición en la lista. La victoria de las candidatas fue el resultado de una astuta estrategia. Un grupo de delegadas se reunieron y decidieron nominar unas pocas candidatas para concentrar el voto. Sólo cinco mujeres se postularon para las primeras ocho posiciones, en contraste con 20 candidatos masculinos. De hecho, varias delegadas, alentadas por sus contrapartes masculinos para que se propusieran, optaron por declinar. Ellas sospechaban que era una táctica de sus competidores para diluir el voto.

Aunque San Salvador fue un caso exitoso para las candidatas mujeres, hubo problemas en otros departamentos. En Ahuachapán, uno de los candidatos líderes inició una campaña de difamación contra Aída Herrera, quien había sido nominada por el movimiento de mujeres. Herrera fue acusada de ser una mujer adinerada, disoluta, que usaba minifaldas y que le gustaba fumar y beber. Estas acusaciones causaron escándalo entre algunos delegados. Según dijeron, un viejo campesino casi sufre un alaque al corazón y anunció "No podemos tener una prostituta como diputada". Para nadie fue una sorpresa que surgieran divisiones entre los delegados y que Herrera no resultara electa. Esto enfureció a varias líderes mujeres hasta tal punto, que insistieron en que se incluyera a Herrera en la plataforma nacional. Argumentaban que la "visión misógina" que se había manifestado en Ahuachapán debía contrarrestarse de inmediato. Temiendo más humillaciones, Herrera al principio se mostró renuente a postularse como candidata. Tras mucha discusión estuvo de acuerdo en que era necesario dejar sentada su posición. Eventualmente fue nominada al séptimo lugar en la lista nacional. Con su nominación, el Consejo Político del FMLN (cuyos miembros eligen los candidatos) envió un fuerte mensaje de apoyo a la igualdad de género.

En la convención del departamento de Chalatenango, "María Chichilco" (María Ofelia Navarrete) desplazó a Eduardo Linares, quien había sido electo en 1994 para representar el departamento. Chichilco, una figura carismática con una larga historia de lucha en el FMLN, también enfrentó una considerable oposición. Miembros del FMLN que se habían afiliado al partido tras los acuerdos de paz en 1992 y quienes no compartían las posiciones ideológicas de los simpatizantes tradicionales, se opusieron a su candidatura. Este sector unió fuerzas con intereses terratenientes quienes le temían a la "radical" líder del FMLN.

En San Vicente, nadie se opuso al liderazgo de Nidia Díaz. Sin embargo, en este caso, viejas rivalidades entre los grupos históricos que conformaban el FMLN causaron problemas. Díaz, una líder del viejo Partido Revolucionario de los Trabajadores Centroamericanos (PRTC), enfrentó la oposición de un sector que había estado afiliado a las Fuerzas Populares de Liberación (FPL) y cuyo líder era Facundo Guardado. Electo coordinador del FMLN en diciembre de 1997, Guardado se pronunciaba a favor de la renovación argumentando que el partido debería nominar a "nuevas fuerzas" en lugar de líderes históricos. Su posición no prosperó. La resistencia a la candidatura de Díaz se superó cuando mujeres identificadas con las FPL convencieron a sus amigos de que Díaz era una candidata óptima dado que ella era una de las líderes más populares del FMLN según los resultados de una reciente encuesta, y que el FMLN perdería volos si ella no aparecía como candidata.

Al igual que en 1994, las mujeres tuvieron mejores resultados a nivel nacional, donde ocuparon un 45 por ciento de las posiciones de candidatos y 50 por ciento de los suplentes. Aunque las listas departamentales fueron elaboradas por los delegados del FMLN electos a la convención departamental, la lista nacional se estableció a partir de los votos de los delegados a la convención nacional, que incluía a los 52 miembros del Consejo Político, la instancia de toma de decisiones más alta después de la Comisión Política compuesta por 15 miembros. A la luz del éxito alcanzado por las mujeres en varios departamentos y especialmente en San Salvador, varios líderes masculinos se mostraron preocupados cuando llegó el momento de preparar la lista nacional. Las mujeres argumentaron a favor de la trenza, es decir, que mujeres y hombres alternaran en la lista. Esta idea no se aprobó y, en su lugar, la votación procedió en varias rondas. Los candidatos fueron electos en listas de cinco, con votos separados para hombres y mujeres. De las cinco primeras posiciones, dos fueron asignadas a mujeres candidatas. En la primera ronda de votación, Ileana Rogel obuuvo la mayoría de los votos y Lorena Peña alcanzó la 
cuarta posición. Sin embargo, a diferencia de los procedimientos de votación utilizados en San Salvador, el orden en que aparecerían los cinco primeros candidatos se estableció a través de una ronda de votos posterior. Schafik Handal, uno de los comandantes históricos del FMLN, obtuvo el primer lugar, desplazando a lleana Rogel, mientras que Peña bajó al quinto lugar. En su caso, en once de los 52 votos no hubo ni uno solo para ella. Aparentemente Peña, quien es tal vez la feminista más abierta dentro del partido, había antagonizado con un número considerable de líderes masculinos. El mismo procedimiento se utilizó para determinar las 15. posiciones restantes. A nivel nacional se nominó a un total de 8 mujeres.

En 1997, las mujeres constituían el 29.8 por ciento de todos los candidatos y suplentes comparado con el 23.2 por ciento en 1994. Este fue un notable avance y sólo estaba un poco por debajo del peso relativo de las mujeres dentro del partido El éxito en el caso de los candidatos a la Asamblea no se repitió a nivel municipal. De los 262 candidatos del FMLN a alcalde, sólo el 6 por ciento cran mujeres, así como un 20 por ciento de los candidatos a la municipalidad. Era evidente que las mujeres habían tenido mucho éxito movilizando sus fuerzas a nivel nacional, así como para las importantes elecciones parlamentarias. Las líderes reconocieron igualmente que sus esfuerzos habían sido más exitosos en las áreas urbanas que en el campo. Uno de los principales obstáculos para incrementar el número de mujeres electas a cargos en la municipalidad fue la renuencia de muchas mujeres a postularse. A la vez, esto fue el resultado de relaciones de género tradicionales, en las que las mujeres están relegadas a la esfera privada. No obstante, el accionar del FMLN fue admirable, especialmente en comparación con otros partidos.

Por su parte, el partido en el gobierno, la Alianza Republicana Nacionalista (ARENA), tenía en sus listas para 1997 un total de 16 mujeres nominadas a la asamblea legislativa. Gloria Salguero Gross, en ese entonces presidenta de la Asamblea Legislativa y una de las tres legisladoras de ARE-
NA electas en 1994, encabezaba la lista nacional. Sin embargo, ella era la única mujer en una posición prominente en la lista. Ni una sola lista departamental estaba encabezada por una mujer, $y$ un dato interesante es que sólo tres de los 20 candidatos de ARENA en la lista nacional eran mujeres. Producto de las débiles posiciones de las mujeres en las listas de candidatos, sólo cuatro mujeres candidatas de ARENA resultaron electas a la Asamblea. La actuación de ARENA indica que el apoyo que recibieron las mujeres del FMLN por parte de sus líderes nacionales no se repitió en el caso del partido en el gobierno. Según las líderes del FMLN, Gloria Salguero Gross reconoció la falta de apoyo para la igualdad de género dentro del partido ARENA. En conversaciones privadas con sus contrapartes en el FMLN, expresó admiración por las destacadas posiciones que ocupaban las candidatas en las listas de este partido.

La experiencia de las militantes del FMLN en El Salvador fue muy similar a los retos que enfrentan las mujeres del FSLN en Nicaragua. A pesar de la importante participación de las mujeres en la lucha revolucionaria, sólo se les dio una limitada representación en el Consejo de Estado. Este órgano corporativo y colegislativo se estableció en 1981, y de sus 51 miembros iniciales nominados por el gobierno revolucionario, sólo cuatro eran mujeres. En 1984, para las primeras elecciones democráticas después de la guerra, las mujeres aumentaron su representación en las listas de candidatos del FSLN. Ese año, el FSLN presentó a 16 mujeres candidatas y 18 suplentes, lo que representaba el 19 por ciento de los 180 candidatos y suplentes para la Asamblea. Sólo unas cuantas mujeres, sin embargo, encabezaban la lista de su región ${ }^{13}$. Tal era el caso de Dora María Téllez y Leticia Herrera, líderes históricas que encabezaban la lista en Managua, así como de Gladys Báez, quien encabezaba la lista de candidatos en Boaco/ Chontales. En uno de los tres distritos electorales en la Costa Atlántica (Zelaya Norte), las tres candidatas eran mujeres, con Dorotea Wilson a la cabeza de la lista. Los otros dos distritos no tenían ninguna mujer candidata.

13. Para las elecciones de 1984 y 1990, los distritos electorales del país estaban conformados por regiones, mientras que en 1996, Nicaragua estaba dividida en departamentos. 
Cuadro 2

\section{Composición de género de los candidatos del FSLN}

a la Asamblea 1984-1996

Elecciones de 1984 y 1990

\begin{tabular}{|c|c|c|c|c|c|c|c|c|c|c|c|c|}
\hline \multirow[b]{2}{*}{ Años } & \multicolumn{4}{|c|}{ Candidatos } & \multicolumn{4}{|c|}{ Suplentes } & \multicolumn{4}{|c|}{ Total } \\
\hline & Mujeres & $\%$ & Hombres & $\%$ & Mujeres & $\%$ & Hombres & $\%$ & Mujeres & $\%$ & Hombres & $\%$ \\
\hline 1984 & 16 & 17.8 & 74 & 82.2 & 18 & 20.0 & 72 & 80.0 & 34 & 18.9 & 146 & 81.1 \\
\hline 1990 & 19 & 21.1 & 71 & 78.9 & 15 & 16.7 & 75 & 83.3 & 34 & 18.9 & 146 & 81.1 \\
\hline
\end{tabular}

Elecciones de 1996

\begin{tabular}{|c|c|c|c|c|c|c|c|c|c|c|c|c|}
\hline \multirow[b]{2}{*}{ Candidalura } & \multicolumn{4}{|c|}{ Candidatos } & \multicolumn{4}{|c|}{ Suplentes } & \multicolumn{4}{|c|}{ Total } \\
\hline & Mujeres & $\%$ & Hombres & $\%$ & $\overline{\text { Mujeres }}$ & $\%$ & Hombres & $\%$ & $\overline{\text { Mujeres }}$ & $\%$ & Hombres & $\%$ \\
\hline $\begin{array}{l}\text { Listas depar- } \\
\text { tamentales }\end{array}$ & 23 & 32.9 & 47 & 67.1 & 24 & 34.3 & 46 & 65.7 & 47 & 33.6 & 93 & 66.4 \\
\hline Lista nacional & 9 & 45.0 & 11 & 55.0 & 8 & 40.0 & 12 & 60.0 & 17 & 42.5 & 23 & 57.5 \\
\hline Total & 32 & 35.6 & 58 & 64.4 & 32 & 35.6 & 58 & 64.4 & 64 & 35.6 & 116 & 64.4 \\
\hline
\end{tabular}

Fuente: Calculado de las listas de candidatos publicadas por el Consejo Supremo Electoral y el FSLN.

Durante la campaña electoral de 1990 , el FSLN presentó 19 candidatas y 15 suplentes. Sólo en la región VI (Matagalpa y Jinotega) una mujer, Doris Tijerino, encabezaba la lista de candidatos. En Managua, Dora María Téllez y Leticia Herrera estaban después de Carlos Núñez Téllez, en ese entonces presidente de la Asamblea. Gladys Báez era candidata en la región III, donde ocupaba el cuarto lugar, mientras que Dorotea Wilson no eslaba postulada para su reelección.

Las listas de candidatos para 1996 - cuando se aplicó por primera vez la cuota del 30 por cien10-, demostró que las mujeres del FSLN habían aumentado de manera considerable su representación en las listas de candidatos del partido. En estas últimas elecciones para la Asamblea, las mujeres representaban el 35.6 por ciento de todos los candidatos y suplentes, comparado con el 18.9 por ciento en 1990. De un total de 90 candidatos, 32 cran mujeres. Al igual que en El Salvador, las mujeres tuvicron más éxito para figurar en la lista nacional. En Nicaragua, los delegados electos a un congreso nacional decidieron sobre la composición de la lista nacional. En ese congreso había miembros de la Asamblea Sandinista, la máxima autoridad partidaria después de la Dirección $\mathrm{Na}$ cional. Mientras que las mujeres candidatas representaban un tercio de las posiciones en las listas departamentales, en la lista nacional tenían el 45 por ciento de los 20 escaños.

Esta imagen positiva, sin embargo, es algo engañosa. Si se consideran las listas departamentales desde la perspectiva de cuántas posiciones seguras ocupaban las mujeres, es evidente que pocas mujeres candidatas del FSLN ocupaban lugares seguros. Sólo en dos casos estaban las listas para los 15 departamentos del país y las dos regiones autónomas encabezadas por mujeres. En Managua, Mónica Baltodano ocupaba el primer lugar en la lista, al igual que Edna Stubbert en Boaco. A nivel municipal, la situación era aún peor, con incluso pocas mujeres propuestas como candidatos.

Esta situación tenía tres motivos fundamentales. Por un lado "hacía falta la buena voluntad por parte de los compañeros masculinos" y la intención de la cuota del 30 por ciento establecida en los estatutos fue subvertida al colocar a las mujeres en posiciones donde tenían pocas posibilidades 
de resultar electas (Wilson, entrevistas del 5 de febrero de 1997). Por otra parte, muchas mujeres simplemente no estaban dispuestas a aceptar su candidalura. Particularmente a nivel local, los prejuicios culturales y la dura realidad económica elevan a un nivel prohibitivo para muchas mujeres el costo de asumir posiciones de liderazgo. Según Wilson, este problema se complicó con la división que hubo en el FSLN en 1995, después de que muchos miembros instruidos y altamente preparados abandonaron las filas del partido cuando Sergio Ramírez estableció el Movimiento de Renovación Sandinista (MRS). Finalmente, a los esfuerzos de las militantes por aumentar la represenlación de las mujeres en las listas de candidatos les faltó coordinación. A diferencia del FMLN en El Salvador, el partido sandinista no liene una secretaría de las mujeres que coordine este lipo de aclividades. Según Mónica Baltodano, Secrelaria de Organización del FSLN, "las leministas" dentro del particlo se oponían a la creación de una secretaría porcue temían que se utilizara para controlar al movimicnto de mujeres (Baltodano. entrevista del 13 de noviembre de 1997).

En 1996. el FSLN convocó un congreso nacional parta establecer la lista nacional y las líderes estaban indignadas ante el hecho de que tan pocas mujeres ocuparan posiciones seguras. Fue entonces que argumentaron a favor de consideraciones especiales a las mujeres a nivel nacional, $y$, para asegurar buenas posiciones, las militantes lograron que los líderes clel particlo adoptaran "la trenzal", doncle hombres y mujeres alternan en las posiciones dentro de las listas. Con la implementación de este procedimiento, cuatro mujeres lograron posiciones seguras.

A pesar de las obvias deficiencias, el accionar sandinista contrasta de manera lavorable con la composición de género de las listas de candidatos presentadas por otros partidos nicaragüenses. Por ejemplo, la Alianza Liberal sólo tenía 8 mujeres candidatas y 14 suplentes en sus listas, ninguna de cllas en posiciones prominentes. Como resultado de esa situación. a pesar de haber ganado las elec- ciones y obtener 42 escaños en la Asamblea, la Alianza Liberal no tenía ni una sola mujer representante. Tres partidos menores, el Movimiento de Renovación Sandinista, el Partido Unido Nicaragüense, Obreros, Campesinos y Profesionales (PUNOCP) y el Partido Alianza Democrática Nicaragüense (PADENIC) tenían candidatas mujeres que encabezaban sus listas nacionales. Los dos últimos partidos no obtuvieron ni un solo escaño, y el único escaño que obluvo el MRS de Sergio Ramírez lo ocupó Jorge Samper, una figura de peso dentro del partido, quien encabezaba la lista en Managua. Samper es también el marido de Rosa Marina Zelaya, la presidenta del Consejo Supremo Electoral. Los sandinistas disidentes obtuvieron tan pocos votos que Dora María Téllez, quien encabezaba la lista nacional, no resultó electa. Igualmente interesante es el hecho de que de los 22 candidatos presidenciales sólo una cra mujer. El Partido Alianza Popular Conservadora apoyó a Miriam Argüello Morales como su candidata. Otro partido pequeño Ienía una mujer candidata a la vice-

presidencia.

\section{Los resultados electorales desde una pers- pectiva de género}

En las clecciones legislativas de 1994, el FMLN luvo resultados respetables. La antigua guerrilla obtuvo 287,811 votos (de un total de 1.3 millones) y ocupó 21 de los 84 escaños en la Asamblea. Después de las elecciones, dos de los grupos históricos del FMLN, el Ejército Revolucionario del Pucblo (ERP) y la Resistencia Nacional (RN), se retiraron del FMLN y crearon su propio partido. Como esos dos grupos tenían un total de siele representantes entre ellos, el número de diputados del FMLN se redujo a 14. ARENA obtuvo 39 escaños $y$, por lo tanto, no tenía una mayoría absoluta en la nueva Asamblea.

A nivel municipal, sin embargo, ARENA barrió en las elecciones, obteniendo 207 de los 262 consejos municipales. El FMLN ganó en sólo 15 ciudades. Este revés lue particularmente significa- 
tivo, debido a que las elecciones locales se reali- $\mid$ todo y, por lo tanto, el FMLN quedó prácticamenzan según un sistema donde el que gana se lleva te fuera del gobierno local ${ }^{14}$.

\section{Cuadro 3}

Mujeres candidatas electas en los comicios salvadoreños de 1994 y 1997

\begin{tabular}{|c|c|c|c|c|c|c|}
\hline \multicolumn{7}{|c|}{ Mujeres electas en las elecciones de 1994} \\
\hline & \multicolumn{3}{|c|}{ Asamblea Legislativa } & \multicolumn{3}{|c|}{ Alcaldes } \\
\hline \multirow[b]{2}{*}{ Partido } & \multicolumn{3}{|c|}{ Total } & \multicolumn{3}{|c|}{ Número Total } \\
\hline & Mujeres & $\%$ & Escaños & Mujeres & $\%$ & de Alcaldes \\
\hline ARENA & 3 & 7.7 & 39 & 30 & 14.5 & 207 \\
\hline FMLN & 5 & 23.8 & 21 & 2 & 13.3 & 15 \\
\hline PDC & 1 & 5.6 & 18 & 0 & 0.0 & 29 \\
\hline $\mathrm{PCN}$ & 0 & 0.0 & 4 & 0 & 0.0 & 10 \\
\hline $\mathrm{CD}$ & 0 & 0.0 & 1 & 0 & 0.0 & 0 \\
\hline $\mathrm{MU}$ & 0 & 0.0 & 1 & 0 & 0.0 & 0 \\
\hline \multirow[t]{4}{*}{ Total } & 9 & 10.7 & 84 & 32 & 12.2 & 262 \\
\hline & \multicolumn{6}{|c|}{ Mujeres electas en las elecciones de 1997} \\
\hline & \multicolumn{3}{|c|}{ Asamblea Legislativa } & \multicolumn{3}{|c|}{ Alcaldes } \\
\hline & \multicolumn{2}{|c|}{ Total } & $\ldots$ & \multicolumn{3}{|c|}{ Número Total } \\
\hline Partido & Mujeres & $\%$ & Escaños & Mujeres & $\%$ & de Alcaldes \\
\hline ARENA & 4 & 14.3 & 28 & 16 & 9.9 & 162 \\
\hline FMLN & 9 & 33.3 & 27 & 6 & 12.5 & 48 \\
\hline PDC & 0 & 0 & 7 & 0 & 0 & 15 \\
\hline PCN & 0 & 0 & 11 & 1 & 5.6 & 18 \\
\hline $\mathrm{CD}$ & 0 & 0 & 2 & 0 & 0 & 0 \\
\hline MU & 0 & 0 & 1 & 0 & 0 & 3 \\
\hline $\mathrm{PD}$ & 0 & 0 & 0 & 0 & 0 & 1 \\
\hline PLD & 1 & 50.0 & 2 & 0 & 0 & 0 \\
\hline PRSC & 0 & 0 & 3 & 0 & 0 & 6 \\
\hline PDC-PD* & 0 & 0 & 3 & 0 & 0 & 4 \\
\hline FMLN-CD* & 0 & 0 & 0 & 0 & 0 & 2 \\
\hline FMLN-MU* & 0 & 0 & 0 & 0 & 0 & 3 \\
\hline Total & 14 & 16.7 & 84 & 23 & 8.8 & 262 \\
\hline
\end{tabular}

Fuentes: FLACSO, El proceso electoral en El Salvador, p. 189, p. 193; Movimiento Salvadoreño de Mujeres (MSM), "Las mujeres salvadoreñas y los resultados electorales", en Las Dignas, Las mujeres, p. 29; Tribunal Supremo Electoral.

Nota: El total incluye un municipio donde ganó un candidato del Movimiento Auténtico Cristiano (MAC).

* Estos partidos formaron una alianza electoral en varios departamentos.

14. La discusión sobre las elecciones de 1994 se obtuvo de Luciak (1996). 
En 1994, la tasa de éxito para candidatos femeninos y masculinos del FMLN había sido casi la misma. Cinco mujeres (de 21) y dieciséis hombres (de 63) que estaban en la lista de candidatos del FMLN resultaron electos. De esa manera, las mujeres constituyeron el 23.8 por ciento de los representantes del FMLN en la Asamblea, una proporción bastante alta según normas internacionales. Como los otros partidos juntos tenían únicamente cuatro mujeres representantes, menos del 11 por ciento de todos los escaños en la Asamblea estaban ocupados por mujeres. De igual manera, pocas mujeres resultaron electas para cl cargo de alcalde. De un total de 262 alcaldes, sólo 32 eran mujeres. De todos los partidos políticos, sólo ARENA y el FMLN tenían representantes mujeres a cse nivel.

En las elecciones de 1997, las mujeres lograron avances considerables. Nueve de las 24 candidatas resultaron electas. Aunque jubilosas, las líderes estaban tristes ante el hecho de que a Aída Herrera le faltaron apenas 1,414 votos $(0.4$ por ciento del voto del FMLN) para unirse a sus amigas en la Asamblea. En el caso de los hombres, 18 de los 60 candidatos luvieron éxito. El hecho de que el 37.5 por ciento de mujeres resultaran electas, comparado con el 30 por ciento de los hombres, indicaba que las militantes sí habían logrado colocar sus candidatas en posiciones seguras. Parte importante de su éxito fue la estrategia para luchar por un tercio de las posiciones seguras y no conformarse con asegurar la cuota en términos del número total de candidatos y suplentes. Al representar las mujeres el 33.3 por ciento de los miembros del FMLN en la Asamblea (en vez de del 28.6 por ciento de los candidatos), el compromiso político del liderazgo del FMLN de asegurar la representación de las mujeres se había convertido en realidad. El FMLN aumentó el número de sus diputados de 14 a $27^{15}$. De los 13 miembros nuevos, seis eran mujeres, lo que significa que la representación de las mujeres en la bancada del FMLN prácticamente se triplicó.

Una vez más el logro de las militantes del FMLN es mucho mayor cuando se le compara con la situación de ARENA. Sólo cuatro de las 16 candidatas del partido gobernante obtuvieron un escaño en la Asamblea. Como a los candidatos masculinos les fue aún peor ( 24 de los 68 candidatos resultaron electos, es decir, una pérdida de 12 representantes masculinos), el peso relativo de las mujeres en la bancada de ARENA aumentó de 7.7 por ciento en 1994 a 14.3 por ciento, con el número total de mujeres pasando de tres a cuatro. Del resto de los partidos en la Asamblea, sólo el Partido Liberal Demócrata tenía una mujer representante. A nivel municipal, las mujeres ocuparon únicamente el 8.8 por ciento de todas las alcaldías. Aunque el FMLN tuvo mejores logros que ARENA en términos de la representación femenina, el hecho de que sólo el 12.5 por ciento de sus alcaldes fuesen mujeres indicaba claramente que el éxito de las militantes del FMLN se limitó al nivel nacional. Sin embargo, cuatro mujeres del FMLN resultaron electas alcaldesas en municipalidades bastante grandes del departamento de San Salvador ${ }^{16}$.

En términos generales, el FMLN se desempeñó excepcionalmente bien. Casi duplicó el número de sus representantes en la Asamblea al ganar 27 escaños, mientras que el de ARENA se redujo de 39 a 28 escaños. Comparado con 1994, la antigua guerrilla obtuvo 82,000 votos, mientras que el par-

15. Aunque el FMLN había obtenido 2 I cscaños en las elecciones de 1994, se quedó con 14 tras el éxodo del grupo que formó el Partido Demócrata.

16. Por este punto, al igual que por muchos otros, estoy en deuda con los cuatro revisores anónimos. 


\section{Cuadro 4 \\ Resultados de las elecciones legislativas de 1994 y 1997 en El Salvador (votos válidos)}

\begin{tabular}{|c|c|c|c|c|}
\hline \multirow[b]{2}{*}{ Partido } & \multicolumn{2}{|c|}{1994} & \multicolumn{2}{|c|}{1997} \\
\hline & Número de votos & $\%$ & Número de votos & $\%$ \\
\hline ARENA & 605,775 & 45.03 & 396,301 & 35.39 \\
\hline FMLN & 287,811 & 21.39 & 369,709 & 33.02 \\
\hline PDC & 240,451 & 17.87 & 93,545 & 8.35 \\
\hline PCN & 83,520 & 6.21 & 97,362 & 8.69 \\
\hline $\mathrm{CD}$ & 59,843 & 4.45 & 39,145 & 3.49 \\
\hline MU & 33,510 & 2.49 & 25,244 & 2.25 \\
\hline MNR** & 9,431 & 0.70 & -- & - \\
\hline MAC** & 12,109 & 0.90 & - & - \\
\hline MSN & 12,827 & 0.97 & 7,012 & 0.62 \\
\hline PLD* & & & 35,279 & 3.15 \\
\hline PRSC* & & & 40,039 & 3.57 \\
\hline PD* & & & 13,533 & 1.20 \\
\hline MAS* & & & 132 & 0.01 \\
\hline PL* & & & 2,302 & 0.20 \\
\hline PUNTO* & & & 0 & 0.0 \\
\hline Total & $1,345,277$ & 100.00 & $1,119,603$ & 100.0 \\
\hline
\end{tabular}

Fuente: Tribunal Supremo Electoral, reportado en FLACSO, El proceso electoral, 1994 , p. 175; Tribunal Supremo Electoral, 1997.

* Este partido no participó en las elecciones de 1994.

** Este partido no participó en las elecciones de 1997.

tido de gobierno perdió a 210,000 de sus antiguos simpatizantes.

Una de las principales victorias para la izquierda fue obtener el control de la capital, así como de otras ciudades importantes. De hecho, aunque el FMLN controlará sólo $53^{17}$ de las municipalidades comparado con las 162 de ARENA, más personas vivirán bajo su gobierno municipal. El FMLN obtuvo más votos en cada departamento que en 1994, a excepción de Morazán, donde recibió 678 votos menos. La débil actuación del FMLN en ese departamento es posiblemente consecuencia de la lucha interna y de la posterior división del partido, cuando sectores del ERP y de la RN se separaron en 1994 para formar el Partido Demócrata (Vickers and Spence, 1994, p. 11). Durante la guerra, el ERP tenía su base social en Morazán. Sus simpatizantes tuvieron dificultad para entender la lucha dentro del liderazgo del FMLN y, por consiguiente, se alienaron de la politica (La Prensa Gráfica, 1 de abril de 1997). El único departamento donde el FMLN no ganó un escaño en la Asamblea fue Usulután. En 1994 le había sucedido lo mismo.

La izquierda revolucionaria en Nicaragua no tuvo tanto éxito como su contraparte salvadoreña para aumentar la representación de las mujeres en su bancada parlamentaria. De los 36 diputados del FSLN que resultaron electos, sólo 8 eran mujeres, y únicamente cuatro candidatas fueron electas de las listas departamentales. Además de las dos mujeres que encabezaban las listas en Managua y Boaco, otra candidata fue electa en Managua. Un desempeño apenas mejor de lo esperado en Chinandega resultó en la elección de Angela Ríos, quien estaba en una precaria cuarta posición. La "trenza" resultó en

17. El FMLN ganó en 48 ciudades y obtuvo 5 municipalidades adicionales como parte de las alianzas electorales. 


\section{Cuadro 5 \\ Composición de género de los miembros del FSLN en la Asamblea 1980-1996}

\begin{tabular}{|c|c|c|c|c|c|c|c|c|c|c|c|c|}
\hline \multirow[b]{2}{*}{ Años } & \multicolumn{4}{|c|}{ Miembros de la Asamblea } & \multicolumn{4}{|c|}{ Suplentes } & \multicolumn{4}{|c|}{ Total } \\
\hline & Mujeres & $\%$ & Hombres & $\%$ & Mujeres & $\%$ & Hombres & $\%$ & Mujeres & $\%$ & Hombres & $\%$ \\
\hline $1980^{*}$ & 4 & 7.8 & 47 & 92.2 & 8 & 15.7 & 43 & 84.3 & 12 & 11.8 & 90 & 88.2 \\
\hline 1984 & 13 & 21.3 & 48 & 78.7 & 13 & 21.3 & 48 & 78.7 & 26 & 21.3 & 96 & 78.7 \\
\hline 1990 & 9 & 23.1 & $30^{* *}$ & 76.9 & 8 & 20.5 & 31 & 79.5 & 17 & 21.8 & 61 & 78.2 \\
\hline 1996 & 8 & 22.2 & $28 * *$ & 77.8 & 15 & 41.7 & 21 & 58.3 & 23 & 31.9 & 49 & 68.1 \\
\hline
\end{tabular}

Fuente: Los cálculos se basan en las listas de miembros suministradas por el FSLN; los datos para 1990 aparecen en Mercedes Olivera. Malena de Montis y Mark Meassick, Nicaragua: El poder de las Mujeres, Managua, Cenzontle, 1992, p. 169.

* En 1980, los miembros del Consejo de Estado fueron nominados por los líderes del FSLN.

** Incluye al derrotado candidato presidencial, Daniel Ortega.

la elección de cuatro mujeres de la lista nacional, dando a las candidatas el mismo grado de éxito que sus contrapartes masculinos (Baltodano, entrevista del 13 de noviembre de 1997).

A nivel departamental, sin embargo, los resultados para las mujeres estuvieron notoriamente malos. De las 23 candidatas, sólo cuatro fueron electas, mientras que 24 de los 47 candidatos masculinos tuvieron éxito. Aparentemente las mujeres del FSLN tenían una posición fuerte, ya que representaban el 33 por ciento de los candidatos departamentales. Sin embargo, la falta de posiciones seguras significó que sólo el 17 por ciento de esas mujeres resultaron electas, comparado con el 51 por ciento de los hombres.

Los resultados electorales significaron un retroceso para los esfuerzos de las militantes por aumentar su presencia en el legislativo. De hecho, la fuerza relativa de las mujeres del FSLN en la Asamblea bajó del 23.1 por ciento en 1990 a 22.2 por ciento.

La actuación del FSLN evidencia que el énfasis en garantizar una cuota para las mujeres no es suficiente. Por el contrario, es necesario poner más energía para asegurar posiciones seguras en las lis- tas. Sin embargo, comparado con sus rivales políticos, el FSLN se desempeñó bastante bien. Sólo otros dos partidos de los que están representados en la nueva Asamblea, el Partido Liberal Constitucionalista (PLC) y el Partido Liberal Independiente (PLI), tenían cada uno una mujer legisladora. A las mujeres también se les dejó fuera del gobierno municipal; y de las 145 ciudades, el FSLN ganó en 52 y la Alianza Liberal en 91. Mientras que el partido de gobierno logró colocar 6 alcaldesas, el FSLN tenía tres.

La Alianza Liberal fue la gran ganadora de las elecciones. Arnoldo Alemán subió a la presidencia, y su partido controla 42 de los 93 escaños en la Asamblea. El FSLN, que documentó una serie de irregularidades, hizo acusaciones de fraude electoral. Al final, sin embargo, los sandinistas aceptaron el veredicto del Consejo Supremo Electoral y decidieron hacer la oposición al nuevo gobierno en el campo legislativo, donde el FSLN controla 36 escaños. Más de la milad de los partidos que participaron en las elecciones no lograron obtener ni un solo escaño.

Cabe señalar que en un contexto regional, la actuación de la izquierda revolucionaria en Nica- 
ragua y El Salvador con respecto a la representación de las mujeres estuvo bastante buena. El número de mujeres legisladoras en las Asambleas centroamericanas es generalmente bajo, aunque tampoco difiere tanto de la situación en muchas sociedades industrializadas. Costa Rica y El Salvador, en particular, son bastante competitivos, según los parámetros internacionales.

Lo que es preocupante para el futuro de la consolidación democrática en los dos países es la disminución en el número de votantes. Las cifras en Nicaragua aún son bastante buenas comparadas con los niveles internacionales, pero en el caso de El Salvador, la falta de interés en el proceso electoral ha alcanzado proporciones de crisis. En las últimas elecciones, el 62 por ciento de los votantes decidieron no votar o invalidaron su voto, fenómeno descrito como "el primer resultado importante

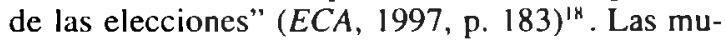
jeres líderes en ambos países sostienen que las mujeres constituyen la mayoría de los votantes. Esta situación plantea serias preguntas sobre el papel y la parlicipación en general de las mujeres en las transiciones en América Central.

\section{Conclusiones}

$=$

revolucionaria de Nicaragua y El Salvador ha mejorado de manera notable. La evidencia más reciente fue que el Consejo Político del FMLN propuso a dos mujeres, Norma Guevara y Violeta Menjívar (junto con Gerson Martínez) como candidatas para el Consejo Ejecutivo de la Asamblea Legislativa. Los tres resultaron electos.

Aún más significativos fueron los resultados de la convención del partido FMLN, celebrada en diciembre de 1997. Violeta Menjívar obtuvo la mayoría de los votos y fue electa a la vicepresidencia del partido. Las militantes lograron mantener un tercio de las posiciones en el comité ejecutivo del partido, y aumentaron su representación en el consejo político de 30 a 40 por ciento (Díaz, entrevista del 9 de diciembre de 1997). Sin embargo, demasiado optimismo es prematuro. En estos momentos, los asuntos de las mujeres reciben frecuente atención de los respectivos líderes del partido, más que todo porque les preocupa su imagen. Es preciso discernir entre los avances positivos en términos de igualdad formal, y una reformulación fundamental de las relaciones tradicionales de género, condición previa para la realización de la igualdad substantiva. En 1995, Salvador Sánchez Cerén, en ese entonces coordinador del FMLN,
En la actualidad, parece que sólo la izquierda está dispuesta a aceptar el reto de la igualdad de género y a revisar la doctrina y las estructuras partidarias con ese fin.
Al analizar las elecciones nicaragüenses y salvadoreñas concuerdo con la opinión de Jack Spence $(1997$, p. 18) en cuanto a que "comparativamente hablando, ambos partidos de la izquierda lograron resultados en los últimos meses que serían la envidia de varias docenas de partidos de la izquierda en el mundo". Desde una perspectiva de género, las estrategias utilizadas por militantes del FMLN y el FSLN para aumentar la representación de las mujeres en cargos públicos son también admirables. Sin duda la posición de las mujeres dentro de la izquierda reconoció que "los niveles de participación de las mujeres son aún bastante bajos, así como los niveles de representación dentro de las diferentes estructuras partidarias" (Sánchez Cercén, entrevista del 3 de mayo de 1995). Durante los dos últimos años, sin embargo, se ha podido evidenciar que el FMLN ha avanzado en la implementación de "una nueva forma de pensar" en lo que respecta a sus constituyentes femeninas. Como parte de ese esfuerzo, en marzo de 1996, la Comisión Política del FMLN decidió aplicar una "perspectiva de géne-

18. Tommie Sue Montgomery (1997, p. 5) argumenta que la alta cifra de abstención es engañosa. Ella resta a los 300,000 salvadoreños que viven en el exterior, los 300,000 muertos que aparecen en los padrones electorales y los 400,000 que nunca retiraron su tarjeta electoral de las oficinas electorales. Así es como obtiene una tasa de abstención del 44 por ciento, que se acerca a la que se reportó en 1994 (FLACSO, 1995, p. 173). Tomando en cuenta, sin cmbargo, que más de 350,000 votantes no retiraron sus tarjetas en 1994 (Spence, Dye y Vickers, 1994, p. 7). y que no existe evidencia alguna de que en $1994 \mathrm{el}$ número de salvadoreños que vive en el exterior o los que aparecen en el padrón electoral aunque estén muertos haya sido diferente a 1997, la reducción en el número de votantes parece ser real. 
ro" en el funcionamiento cotidiano del partido, con el fin de aumentar la sensibilidad de su membresía acerca de las dificultades que enfrentan las mujeres dentro del partido y en la sociedad en general (Sánchez Cerén, entrevista del 29 de abril de 1996). Los miembros de la Comisión estuvieron incluso de acuerdo en que era necesario que ellos se familiarizaran con la teoría de género, y aceptaron sesiones de capacitación ofrecidas por la secretaría de las mujeres.

En un avance similar, la Dirección Nacional Sandinista en Nicaragua recientemente participó en un seminario sobre teoría de género, donde escucharon durante cuatro horas a una especialista sobre el tema. Cuando concluyó la actividad, varios miembros de la Dirección dijeron estar asombrados de que su comportamiento hacia las mujeres tuviera sus raíces en el machismo, y dijeron actuar de esa manera "porque lo consideraban natural" (Wilson, entrevista del 5 de febrero de 1997).

En Nicaragua, el clima político nacional no favorece la emancipación de las mujeres. En febrero de 1997, el presidente Alcmán trató de hacer que la Asamblea Nacional aprobara la creación de un Ministerio de la Familia, que supuestamente reemplazaría al Instituto Nicaragüense de la Mujer (INIM). Sólo la rápida movilización del movimiento de mujeres en oposición a esa propuesta -que consideraban una amenaza para las instituciones que están a favor de los derechos de la mujer-, impidió la aprobación inmediata de tal iniciativa. La propuesta fue enviada a una comisión de la Asamblea dando así tiempo al movimiento de mujeres para convencer a los legisladores de que era preciso preservar el INIM. A pesar de tendencias contrapuestas, el movimiento de mujeres en Nicaragua está creciendo cada vez más fuerte y más cohesionado, mientras que las militantes del FSLN siguen luchando por ampliar sus esfuerzos organizativos desde el nivel nacional a las estructuras intermedias del partido. Es interesante observar que la situación en El Salvador es totalmente opuesta. Las mujeres del FMLN han tenido éxito en su lucha por la igualdad de género dentro del partido, mientras que en las últimas elecciones el movimiento de mujeres no logró montar un esfuerzo organizativo fuerte. Esto plantea preguntas sobre las lecciones que se pueden aprender de ento estudio comparativo de la experiencia salvedoroha y nicaragüense.

En la actualidad, parece que sólo la izquierda está dispuesta a aceptar el reto de la igualdad de género y a revisar la doctrina y las estructuras partidarias con ese fin. Es así que los esfuerzos continuos por parte de los militantes del partido tienen posibilidades de ser exitosos. Sin embargo, es preciso ampliar esos esfuerzos e incorporarlos a alianzas pluralistas para que tengan un impacto en las relaciones de género de la sociedad en su conjunto. La unidad, y la ausencia de disputas internas, son condiciones previas para que el movimiento de mujeres se convierta en un defensor eficaz de los derechos de las mujeres y ejerza presión en las partidos políticos para que adopten la bandera de la igualdad de género. Además, aunque la implementación de medidas cuantitativas de 'discriminación positiva' como las cuotas, son parte esencial de la lucha para aumentar la representación de las mujeres en el ámbito público, el demasiado énfasis en ellas puede fácilmente atrapar a las mujeres en una mera igualdad estadística y no llevarlas a una presencia verdaderamente equitativa en los cargos públicos. Esto también indica que la lucha aún está en la etapa de asegurar la equidad formal.

A partir de las experiencias del proceso para la selección de candidatos en ambos países, es evidente que en esta coyuntura, la lucha por la igualdad de género continúa siendo básicamente un fenómeno urbano. Una encuesta reciente, entre más de 200 mujeres militantes del FMLN en tres municipalidades rurales ${ }^{19}$, reveló que el movimiento de mujeres necesita ir hacia sus constituyentes rurales y llevar al campo el debate sobre los derechos de la mujer. También indicó que, al menos en el caso de la izquierda salvadoreña, el centro de la resistencia hacia la emancipación de las mujeres está ubicado en las estructuras departamentales y locales. Mientras que los hombres se resisten porque se sienten amenazados, las mujeres están renuentes a aceptar la responsabilidad del cargo público sin la necesaria red de apoyo. Varias mujeres que respondieron la encuesta argumentaron que a la luz de las difíciles condiciones económicas, ellas no podían darse el lujo de estar activas dentro del

19. Encuesta realizada durante $1995-96$ por el autor y un equipo de entrevistadores, en las municipalidades de San Esteban Catarina, Meanguera y San José Las Flores. 
partido. Aunque las mujeres militantes dijeron que apoyaban al FMLN, tenían poco o ningún conocimiento sobre lo que estaba sucediendo a nivel nacional, una situación que contrasta fuertemente con la de sus contrapartes masculinos.

Finalmente, queda claro que la lucha por la igualdad de género es un proyecto a largo plazo. Es la acumulación de experiencias la que permite el surgimiento de estrategias eficaces. En Nicaragua, muchas mujeres empezaron a replantearse su papel dentro de la sociedad durante la revolución sandinista. La destreza que se adquirió durante los años ochenta en la organización de las bases a favor de la revolución, demostró ser útil en la creación de un fuerte movimiento de mujeres. De igual manera, el éxito que actualmente tienen las militantes del FMLN en hacer que la igualdad de género sea un tema central dentro del partido, tiene sus raíces en la "exlensa red de organizaciones y contactos personales" que las mujeres miembros del FMLN cultivaron durante la guerra (Hipsher, 1997, p. 11) Los militantes de ambos partidos eslán conscientes de que la lucha por la igualdad de género apenas comienza. En este sentido, los avances logrados hasta ahora son prometedores.

\section{Referencias bibliográficas}

Alvarez. S., Engendering Democracy in Brazil: Women's Movements in Transition Politics, Princeton: Princelon University Press, 1990.

Baltodano. M., Entrevista del autor con Mónica Baltodano. secretaria de organización del FSLN. Managua. noviembre 13, 1997.

Blandón, M.T., Entrevista del autor con María Teresa Blandón, coordinadora del colectivo de mujeres La Malinche, Managua, 4 de febrero, 1997.

Carver. T.. Gender is not a Synonym for Women, Boulder: Lynne Rienner, 1996.

Coalición Nacional de Mujeres, Agenda Mínima, Managua, marzo de 1996.

Chávez Metoyer, C.. "The Women's Movement in the 1996 Nicaraguan Elections". Documento presentado ante el XX International Congress of the Latin American Studies Association, Guadalajara, México: abril, 1997, pp. 17-19.

Cheync, D.. Entrevista del autor con Deysi Cheyne, coordinadora del Instituto para la Investigación, Capacitación y Desarrollo de las Mujeres (IMU), San Salvador. 19 de marzo, 1997.

Chuchryk. P.M... "Women in the Revolution", en Thomas W. Walker (ed.), Revolution and Counterrevolution in Nicaragua, Boulder: Westview, 1991.
Díaz, N., Entrevista telefónica del autor con Nidia Díaz, miembro del comité ejecutivo del FMLN, San Salvador, 9 de diciembre, 1997.

Estudios Centroamericanos (ECA), "Editorial”, Año LII, marzo-abril, 1997.

Facultad Latinoamericana de Ciencias Sociales (FLACSO), El Proceso Electoral 1994, San Salvador: Universidad Centroamericana, 1995.

Ferrey, A., Entrevista del autor con Azucena Ferrey, exmiembro de la Asamblea Nacional y de la Dirección de la Resistencia Nicaragüense, Managua, 12 de noviembre, 1997.

Frente Farabundo Martí para la Liberación Nacional (FMLN), "Carta de principios y objetivos". En FMLN, Documentos Políticos, San Salvador: Ediciones Alternativa, 1993.

Frente Sandinista de Liberación Nacional (FSLN), Progruma histórico del FSLN, Managua, Departamento de Propaganda y Educación Política del FSLN. 1969.

Hecht Oppenheim, L., Democracy in Post 1990 Chile and the Political Incorporation of Women. Documento presentado ante el Meeting of the Latin American Studies Association en 1995, Washington D.C., septiembre, 1995, pp. 28-30.

Hipsher. P., "The Micromobilization of the Feminist Movement in Democratizing El Salvador". Documento presentado ante el XX International Congress of the Latin American Studies Association, Guadalajara, México, abril, 1997, pp. 17-19.

Huntington, S., The Third Wave: Democratization in the late twentieth century, Norman and London: Universily of Oklahoma Press, 1991.

Inter-American Development Bank (IDB), Women in the Ainericas: Bridging the Gender Gap, Washington, D.C.: Inter-American Development Bank, 1995.

Kampwirth, K., "Feminism, Anti-Feminism and Electoral Politics in Post-war Nicaragua and El Salvador". Documento presentado ante el 1995 Annual Meeting of the American Political Science Association, Chicago, IL: 31 de agosto-2 de septiembre, 1995.

La Prensa Gráfica, I de abril, 1997.

Luciak, I., "El Género y la Izquierda Revolucionaria: El Caso de El Salvador". En María Luisa Tarrés (comp.), Género y Cultura en América Latina, México: El Colegio de México, 1998.

Luciak, I., "Gender and Democratization in El Salvador". Documento presentado ante el 1996 Annual Meeting of the American Political Science Association, San Francisco, 29 de agosto-1 de septiembre, 1996.

Luciak, I., The Sandinisia Legacy: Lessons from a Political Economy in Transition, Gainesville: University Press of Florida, 1995.

Matland, R. y Taylor, M.. "Electoral System Effects on Women's Representation: Theoretical Arguments and Evidence from Costa Rica", Comparative 
Political Studies, Vol. 30, No. 2, 1997, pp. 186-210.

Menjívar, V., Entrevista del autor con Violeta Menjívar, miembro de la Asamblea Legislativa y de la Comisión Polílica del FMLN, San Salvador, 6 de febrero, 1997.

Molina, N., "Propuestas políticas y orientaciones de cambio en la situación de la mujer". En Manuel Antonio Garretón (ed.), Propuestas Políticas y Demandas Sociales, Vol. 3, Santiago: FLACSO, 1989.

Montgomery, T.S., "El Salvador's Extraordinary Eleclions" LASA Forum, Vol. XXVII, No. 1, 1997, pp. 48.

Movimiento Salvadoreño de Mujeres (MSM), "Las mujeres salvadoreñas y los resultados electorales", San Salvador, Documento mimeografiado.

Mujeres por la Dignidad y la Vida (Las Dignas), Las mujeres: ante, con, contra, desde, sin, tras... el poder político, San Salvador: Las Dignas, 1995.

Olivera, M., M. de Montis y M. Meassick, Nicaragua: El poder de las mujeres, Managua: Cenzontle, 1992.

Parvikko, T.. "Conceptions of Gender Equality: Similarily and Difference". En Elizabeth Meehan and Selma Sevenhuijsen (eds.), Equality, Politics and Gender, London: Sage, 1991.

Peña. L., Entrevista del autor con Lorena Peña, miembro de la Asamblea Legislativa y del Consejo Político del FMLN. San Salvador, 7 de febrero, 1997.

Pérez Alemán, P., Organización, Identidad y Cambio: Las Campesinas en Nicaragua. Managua: CIAM/ Editorial Vanguardia, 1990.

Ramírez-Horton, S., "The Role of Women in the Nicaraguan Revolution”. En Thomas W. Walker (ed.), Nicaragua in Revolution. New York: Praeger, 1982.

Randall, M.. Sandino's Daughters: Testimonies of Nicaraguan Women in Struggle, Vancouver: New Star Books, 1986.
Reif, L. L., "Women in Latin American Guerrilln Movements: A comparative Perspective", Comparatlve Politics, Vol. 18, No. 2, enero, 1986.

Saint-Germain, M., "Mujeres '94: Democratic Transltion and the Women's Movement in El Salvador". Documento inédito.

Sánchez Cerén, S., Entrevista del autor con Salvador Sánchez Cerén, coordinador del FMLN, San Salvador, abril, 1996, p. 29.

Sánchez Cerén, S., Entrevista del autor, San Salvador, 3 de mayo, 1995.

Spence, J., "Post War Transitions: Elections and Political Parties in El Salvador and Nicaragua". Documento presentado ante el XX International Congress of the Latin American Studies Association, Guadalajara, México, abril, 1997, pp. 17-19.

Spence, J.; Dye, D. R.; Lanchin, M.; Thale, G. y Vickers, G., "Chapultepec: Five Years Later", Hemisphere Initiatives, Cambridge, MA, enero, 1997.

Spence, J.; Dye, D. R. y Vickers, G., "El Salvador: Elections of the Century", Hemisphere Initiatives, Cambridge, MA, julio, 1994.

Vickers, G. y Spence, J., "Elections: The Right Consolidates Power", NACLA, Vol. XXVIII, No. I, julioagosto, 1994.

Waylen, G., Gender in Third World Politics, Boulder, CO: Lynne Rienner, 1996.

Wilson, D., Entrevista del autor con Dorotea Wilson, miembro de la Dirección Nacional del FSLN, Managua, 5 de febrero, 1997.

Zalaquett, M., Entrevista del autor con Mónica Zalaquett, coordinadora de la Coalición de Mujeres, Managua, 4 de febrero, 1997. 